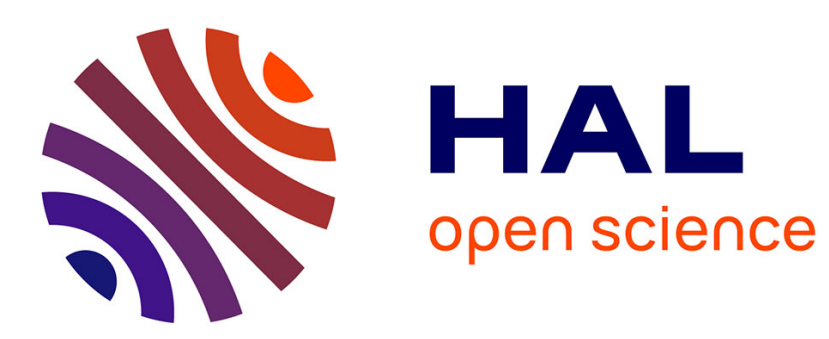

\title{
A survey on multichannel assignment protocols in Wireless Sensor Networks
}

\author{
Ridha Soua, Pascale Minet
}

\section{To cite this version:}

Ridha Soua, Pascale Minet. A survey on multichannel assignment protocols in Wireless Sensor Networks. IFIP Wireless Days (WD), Oct 2011, Niagara Falls, ON, Canada. pp.1 - 3, 10.1109/WD.2011.6098201 . hal-00863355

\section{HAL Id: hal-00863355 \\ https://hal.science/hal-00863355}

Submitted on 20 Sep 2013

HAL is a multi-disciplinary open access archive for the deposit and dissemination of scientific research documents, whether they are published or not. The documents may come from teaching and research institutions in France or abroad, or from public or private research centers.
L'archive ouverte pluridisciplinaire HAL, est destinée au dépôt et à la diffusion de documents scientifiques de niveau recherche, publiés ou non, émanant des établissements d'enseignement et de recherche français ou étrangers, des laboratoires publics ou privés. 


\title{
A Survey on Multichannel Assignment Protocols in Wireless Sensor Networks
}

\author{
Ridha Soua and Pascale Minet \\ INRIA \\ Rocquencourt \\ 78153 Le Chesnay cedex, France \\ Email: ridha.soua@inria.fr, pascale.minet@inria.fr
}

\begin{abstract}
Micaz motes can communicate on multiple frequencies as specified in the 802.15.4 standard. This reality has given birth to multichannel communication paradigm in Wireless Sensor Networks (WSNs). Obviously, multichannel communication mitigates interferences, jamming and congestion, whereas it brings also challenging issues. Thus, in this paper, we are motivated to draw a picture of multichannel assignment protocols in WSNs. After having identified the reasons of resorting to multichannel communication paradigm in WSNs and the specific issues that should be tackled, we propose a classification of multichannel assignment protocols, pointing out different channel selection policies, channel assignment methods and channel coordination techniques. We conclude by a recapitulative table including many examples of existing multichannel protocols designed for WSNs.
\end{abstract}

\section{INTRODUCTION}

Wireless ad hoc networks cannot provide reliable and timely communication with high data rate in the presence of high contention and internal (co-channel) interference. Briefly, researchers have proposed solutions that use adaptive power control, directional antennas and multiple frequency channels. Nevertheless, this plethora of multichannel solutions for ad hoc networks [1] are not adequate for WSNs and cannot be directly applied. First, a sensor node is a miniature device equipped with a single radio transceiver such as the CC2420 so it can only use one channel at a time. Second, energy budget constraints and bandwidth limitation constitute a restriction to apply existing multichannel protocols [2].

Typically, multichannel protocols involves two major steps: 1) channel assignment to nodes and 2) medium access control. In channel assignment, each sensor is assigned a physical channel. Each node should know which channel to use to transmit unicast packets to any connected sensor in its vicinity.

\section{ISSUES IN MULTICHANNEL COMMUNICATIONS}

Compared to single channel communication, multichannel communication rises new problems or makes existing ones more complex:

- multichannel hidden node: The hidden node problem occurs when the node misses an RTS/CTS exchanged on one channel while listening on another [3].

- multichannel deaf node: This occurs when the destination node and the sender are not tuned on the same channel.

978-1-4577-2028-4/11/\$26.00 (c) 2011 IEEE
- interfering channels: We distinguish as in [4] interchannel interference and intra-channel interference.

- channel switching: If each node has its own channel distinct from its neighbors, the end-to-end transmission of a message from a sensor node to the sink requires as many channel switchings as the number of visited nodes.

- low duty cycling device support: To save energy, nodes resort to low duty cycles alternating large sleep periods and small active periods.

- broadcast support: The open question is how to support broadcast in multichannel communication in order to advertise some information with a regional scope?

- QoS support: All messages have neither the same importance degree nor the same requirements from the application point of view. Service differentiation is required.

- autoadaptivity: The multichannel protocol should be environment aware. Channels perturbed by external sources or other coexisting wireless networks must be avoided.

- scalability: Multichannel communication protocols should be designed to support large and/or dense WSNs.

- in network processing support: Some processing of the sampled data could be done in the network to alleviate the amount of data transferred.

\section{BENEFITS EXPECTED FROM MULTICHANNEL COMMUNICATIONS}

Benefits brought by multichannel communications are important and they can be summarized as follows:

- increase dramatically parallel transmission by assigning different channels to adjacent nodes.

- increase data delivery ratio.

- improve data gathering delay and as a consequence the freshness of collected data leading to a more accurate monitoring.

- enhance robustness in the presence of interference, jamming and noise.

\section{ClassificAtion OF EXISTING MULTiCHANNEL ASSIGNMENT PROTOCOLS IN WSNS}

Any multichannel communication protocol has two components: (1) a channel assignment method that will be detailed in the following of this paper and (2) a MAC method. MAC methods can be classified in three families: contention based 
(CSMA/CA), schedule based (TDMA) and hybrid (Z-MAC [5], TDMA-ASAP [6]). In this paper, we focus on multichannel assignment. To classify existing multichannel assignment protocols we ask three questions:

(1) When or at which frequency is the channel assignment invoked? The answer allows us to distinguish between static, semi-dynamic and dynamic channel assignment methods in Section IV-A.

(2) Which channel is selected? The answer is given by the channel selection policy presented in Section IV-B.

(3) How does it work? The answer depends on the channel coordination technique used: see Section IV-C.

\section{A. Channel assignment method}

Channel assignment methods can be categorized according to the frequency of channel assignment. We distinguish three categories:

- static: where channel assignment is done once, at network initialization. Both TMCP [7] and MCRT [8] adopt the static channel assignment approach.

- semi-dynamic: where channel assignment is done at a medium frequency to adapt to changes in channel or even traffic conditions. This channel assignment can be done periodically or be event-based. Semi-dynamic family includes many protocols such as MMSN [9], TACA [10], EM-MAC [11], RMCA [12] and ARM [13].

- dynamic: where channel assignment is done very frequently, typically before each transmission. Y-MAC [14] and MuChMAC [15] belong to this category.

The new trend in channel assignment protocols favors semidynamic channel assignment that represents the best trade-off between low overhead and high adaptivity.

\section{B. Channel selection policy}

The channel is generally selected from a Preferable Channel List [1], denoted PCL. To avoid the use of a busy channel at the receiver, this list is computed either by the receiver like in EMMAC [11] or by exchanging the sender and receiver lists like in MMAC [16]. To select a channel from the PCL, different policies are possible: Round Robin like in EM-MAC, least chosen channel, least load channel or probabilistic method like in RMCA and ARM.

\section{Channel coordination}

To allow communication betwen them, the sender and the receiver must be on the same channel during the transmission time. This requires channel coordination which can be:

- implicit when nodes implicitly agree on 1) the channel to switch and 2) when the channel switching occurs. Among protocols using implicit coordination we distinguish those:

- based on islands of communication: The sink plays the role of gateway between these islands. Each island of communication uses its own channel for internal communications. A PAN coordinator may manage several islands of communication each on its own channel like in IEEE 802.15.4. Another example is given by TACA [10].

- using frequency hopping: Nodes hop from channel to channel. They follow either a common hopping sequence generally given by a centralized entity (e.g. the master of the considered Piconet in Bluetooth [17]) or independent hopping sequences. Each node has its own hopping sequence.

- explicit where nodes decide to negotiate channel selection or scheduling schemes to coordinate channel switching. We distinguish different techniques:

- dedicated control channel: one channel is intended exclusively for control traffic, whereas the remaining channels are used for data traffic. Each node listens to the control channel to know the channel it must switch to for its communication to take place, like in ARM [13]. This mechanism can drastically reduce bandwidth use efficiency if the amount of data exchanged after each rendezvous or the number of available channels is small. When the number of channels increases, the control channel may become a bottleneck.

- splitting phase: time is split into alternating periods of control and data phases. In a control phase, all nodes listen to the control channel to make an agreement. In the data phase, sensors switch to their respective channels negotiated in the previous control phase to exchange data in parallel. An example is given by MMSN [9] for a contention based MAC protocol and by Y-MAC [14] for a scheduled access MAC protocol. The crucial asset of this technique is to solve the deafness and hidden node problems. However, it may suffer from channel inefficiency: channels dedicated to data transmission remain unused in control phase.

- Game theory: The target of the game for example can be the reduction of the total interference in the network. Each player modeling a sensor node, picks up a channel different from its interfering players. The panoplies of player strategy constitute the channel coordination and assignment [18], [12]. This innovative technique has the advantage of being highly distributed and requiring the exchange of limited information to judiciously assign channels such as RMCA [12]. Nevertheless, convergence of game based protocols is still nontrivial.

- node coloring based: A channel assignment problem is typically modeled as a graph coloring problem. The technique consists in covering all sensor nodes (vertices) with the minimum number of channels (colors) such that adjacent nodes have different channels. This approach used in MMSN [9] and TACA [10], entails the pros and cons of node coloring schemes. 
TABLE I

CLASSIFICATION AND ANALYSIS OF EXISTING MULTICHANNEL ASSIGNMENT PROTOCOLS.

\begin{tabular}{|c|c|c|c|c|c|c|c|c|c|c|}
\hline & \multicolumn{2}{|c|}{ Static } & \multicolumn{5}{|c|}{ Semi-dynamic } & \multicolumn{2}{|c|}{ Dynamic } \\
\hline & & $\begin{array}{c}\text { TMCP } \\
{[8]}\end{array}$ & $\begin{array}{c}\text { MCRT } \\
{[9]}\end{array}$ & $\begin{array}{c}\text { MMSN } \\
{[2]}\end{array}$ & $\begin{array}{c}\text { TACA } \\
{[10]}\end{array}$ & $\begin{array}{c}\text { EM-MAC } \\
{[11]}\end{array}$ & $\begin{array}{c}\text { RMCA } \\
{[12]}\end{array}$ & $\begin{array}{c}\text { ARM } \\
{[13]}\end{array}$ & $\begin{array}{c}\text { Y-MAC } \\
{[14]}\end{array}$ & $\begin{array}{c}\text { MuChMAC } \\
{[15]}\end{array}$ \\
\hline \multirow[t]{4}{*}{ Goals } & Parallel transmissions & $\sqrt{ }$ & & $\sqrt{ }$ & & $\sqrt{ }$ & & & & \\
\hline & Increase capacity & & & & $\sqrt{ }$ & & & & & \\
\hline & Enhance robustness & & & & $\sqrt{ }$ & $\sqrt{ }$ & $\sqrt{ }$ & & & \\
\hline & Reduce delays & $\sqrt{ }$ & $\sqrt{ }$ & & & & & & & \\
\hline \multirow[t]{7}{*}{ Properties } & Autoadaptive & & & & $\sqrt{ }$ & & & & & \\
\hline & Broadcast & $\sqrt{ }$ & & $\sqrt{ }$ & & & & $\sqrt{ }$ & $\sqrt{ }$ & $\sqrt{ }$ \\
\hline & QoS & & $\sqrt{ }$ & & $\sqrt{ }$ & & $\sqrt{ }$ & & & \\
\hline & Energy efficient & & & & & & & $\sqrt{ }$ & $\sqrt{ }$ & $\sqrt{ }$ \\
\hline & Channel switching & $\sqrt{ }$ & $\sqrt{ }$ & & & & & & & \\
\hline & Reduced interf. & $\sqrt{ }$ & $\sqrt{ }$ & & $\sqrt{ }$ & $\sqrt{ }$ & & & & \\
\hline & Scalable & & & & & & & $\sqrt{ }$ & $\sqrt{ }$ & \\
\hline \multirow{4}{*}{$\begin{array}{l}\text { Channel } \\
\text { Selection }\end{array}$} & RR & & & & & $\sqrt{ }$ & & & $\sqrt{ }$ & $\sqrt{ }$ \\
\hline & least chosen & & & $\sqrt{ }$ & & & & & & \\
\hline & least loaded & & & & $\sqrt{ }$ & & & & & \\
\hline & probabilistic & & & & & & $\sqrt{ }$ & $\sqrt{ }$ & & \\
\hline \multirow{6}{*}{$\begin{array}{c}\text { Channel } \\
\text { coordination }\end{array}$} & Dedicated ctl channel & & & & & & & $\sqrt{ }$ & $\sqrt{ }$ & \\
\hline & Splitting phase & & & & & & & & & \\
\hline & Game theory & & & & & & $\sqrt{ }$ & & & \\
\hline & Node coloring & & & $\sqrt{ }$ & $\sqrt{ }$ & & & & & \\
\hline & Communication island & $\sqrt{ }$ & $\sqrt{ }$ & & & & & & & \\
\hline & Frequency hopping & & & & & $\sqrt{ }$ & & & $\sqrt{ }$ & $\sqrt{ }$ \\
\hline & MAC & CSMA/CA & CSMA/CA & CSMA/CA & CSMA/CA & & & CSMA/CA & TDMA & $\begin{array}{l}\text { TDMA } \\
\text { XMAC }\end{array}$ \\
\hline \multicolumn{2}{|c|}{ Solution maturity } & $\begin{array}{l}\text { simul } \\
\text { testbed }\end{array}$ & simul & simul & simul & testbed & simul & $\begin{array}{l}\text { simul } \\
\text { testbed }\end{array}$ & simul & testbed \\
\hline
\end{tabular}

\section{Discussion}

In this subsection, we study the relationships between channel assignment and channel coordination techniques.

- frequency hopping is used in dynamic channel assignments, although it could be used also in semi-dynamic assignments.

- dedicated control channel can be used in the three types of channel assignments.

- splitting phase can be used in semi-dynamic and dynamic assignments.

- game theory and node coloring can be used in semidynamic assignment. Their use in dynamic environment does not seem realist as long as the overhead induced is too high.

\section{TAXONOMY PROPOSED}

The taxonomy of multichannel protocols we propose is based on the four questions: 1) what is the goal? 2) when channel assignment is done? 3) which channel is selected? and 4) how channel assignment is done?

Table 1 analyzes some existing multichannel assignment protocols according to these criteria and distinguish between solutions that have been really implemented from those that have been only simulated. Experimentations on a real testbed representative of the environment in which the WSN will be deployed is of paramount importance to make a real validation of the solution. Testbeds like SensLab [19], allow the designers to test their solution with a large number of nodes and/ or a high node density, in realistic conditions.

\section{CONCLUSION}

In this paper, we have considered the challenges raised by multichannel communications, mainly frequency of channel assignment, channel selection policy and channel coordination technique. Then, we have proposed a comprehensive classification of well known multichannel assignment protocols in WSNs. Although multichannel communication is a promising paradigm that is shaping novel applications for WSNs, there are still many challenges that need to be solved such as energy efficiency, non negligible channel switching overhead and support of bursty traffic.

\section{REFERENCES}

[1] J. Crichigno, M. Wu, W. Shu, "Protocols and architectures for channel assignment in wireless mesh networks," Ad Hoc networks, pp. 1051-1077, 2008

"Wey on multichannel communication in wireless sensor networks," Computer Networks, 2011. J.So, N. Vaidya, "Multi-Channel MAC for Ad Hoc Networks: Handling Multi-Channel Hidden Terminals Using A Single Transceiver," In Proc. ACM MobiHoc'04, Tokyo, Japan, 2004.

V. Raman, N. H. Vaidya, "Adjacent Channel Interference Reduction in Multichannel Wireless Networks Using Intelligent Channel Allocation," Technical Report, August 2009.

I. Rhee, A. Warrier, M Aia, J. Min, "Z-MAC: a hybrid MAC for wireless sensor networks," In Proc. ACM SenSys'05, S Diego, USA, November 2005

S. Gobriel, D. Mousse, R. Cleric, "TDMA-ASAP: sensor network TDMA scheduling with adaptive slot stealing and parallelism," In Proc. ICDCS'09, Montreal, Canada, June 2009.

Y. Wu, J. Stankovic, T. He, S. Lin, "Realistic and efficient multi-channel communications in wireless sensor networks." In Proc. INFOCOM'08, pp. 1193-1201, Phoenix, AZ, USA, 2008.

X. Wang, X. Wang, X. Fu, G. Xing, N. Jha, "Flow-Based Real-Time Communication in Multi-Channel Wireles Sensor Networks," In Proc. EWSN'09, Cork, Ireland, 2009.

G. Zhou, C.D. Huang, T. Yan, T. He, J.A. Stankovic, T.F. Adbelzaher, "MMSN: Multi-frequency media access contro

for wireless sensor networks," In Proc. IEEE INFOCOM'O6, Barcelona, Catalunya, Spain, 2006.
[10] Y. Wu, M. Keally, G. Zhou, W. Mao, "Traffic-Aware Channel Assignment in Wireless Sensor Networks," Wireless Algorithms, Systems, and Applications, Lecture Notes in Computer Science, vol. 5682, 2009.

1] L. Tang, Y. Sun, O. Gurewitz and David B. Johnson, "EM-MAC: A Dynamic Multichannel Energy-Efficient MAC

Protocol for Wireless Sensor Networks," In Proc. ACM MobiHoc'11, Paris, France, 2011.
12] Q. Yu, J. Chen, Y. Sun, Y. Fan, W. Shen, "Regret Matching Based Channel Assignment for Wireless Sensor Networks,"

In Proc. IEEE ICC'10, Cape Town, South Africa, 2010.
J. Li, D. Zhang, L. Guo, S. Ji, Y. Li, "ARM: An asynchronous receiver-initiated multichannel MAC protocol with duty cycling for WSNs," In Proc. IEEE IPCCC'10, Albuquerque, NM, 2010.

[14] Y. Kim, H. Shin, H. Cha, "Y-MAC: An Energy-Efficient Multi-channel MAC Protocol for Dense Wireless Sensor Networks," In Proc. IPSN'08, St. Louis, Missouri, USA, 2008.

[15] J. Borms, K. Steenhaut, B. Lemmens, "Low-Overhead Dynamic Multi-channel MAC for Wireless Sensor Networks," In Proc. EWSN'10, Coimbra, Portugal, 2010.

[16] J. So, N. Vaidya, "Multi-channel MAC for ad-hoc networks: handling multi-channel hidden terminal using a single transceiver," In Proc. ACM MobiHoc'04, Tokyo, Japan, 2004.

[17] http://www.ieee802.org/15/

[18] Q. Yu, J. Chen, Y. Fan, X. Shen, Y. Sun, "Multi channel assignment in wireless sensor networks: a game theortic approach," In Proc. INFOCOM'10, San Diego, CA, 2010.

[19] www.senslab.info/ 